\title{
The effect of summarizing strategy on reading comprehension of Iranian intermediate EFL learners
}

\author{
Hooshang Khoshsima, Forouzan Rezaeian Tiyar* \\ Faculty of Management and Humanities, Chabahar Maritime University, Chabahar, Iran \\ Email address: \\ khoshsima@cmu.ac.ir (H. Khoshsima), f.rezaeiantiyar@yahoo.com (F. R. Tiyar)
}

\section{To cite this article:}

Hooshang Khoshsima, Forouzan Rezaeian Tiyar. The Effect of Summarizing Strategy on Reading Comprehension of Iranian Intermediate EFL Learners. International Journal of Language and Linguistics. Vol. 2, No. 3, 2014, pp. 134-139.

doi: $10.11648 /$ j.ijl1.20140203.11

\begin{abstract}
Reading comprehension plays a significant role in educational success. In spite of its importance, students still have difficulties in understanding texts. One solution to the problem of poor reading comprehension is the learning of reading strategies. The current study examined the effect of summarizing strategy on reading comprehension of Iranian intermediate EFL learners. Sixty-one students were selected and randomly divided into two control and experimental groups. The homogeneity of their proficiency level was established using a TOEFL proficiency test. All students in both groups participated in a reading comprehension test as pretest. The experimental group utilized summarizing strategy three times a week typically 45 minutes in duration for ten weeks. After each two week instruction, an immediate posttest was administered. At the end of the treatment, a post-test was administered to both groups. The findings of the study indicated that summarizing strategy has a significant effect on learners' reading comprehension.
\end{abstract}

Keywords: Reading Strategy, Summarizing Strategy, Reading Comprehension, EFL Learners

\section{Introduction}

Well-developed reading comprehension ability is considered the major goal to students' educational success. Since reading is a complex cognitive process; it is of great importance for teachers to train students to be able to take active control of their own comprehension process. Therefore, one of the basic parts of learning a foreign language is mastering learning. The process of creating learners who become successful and autonomous at various stages of learning, results in learning the content more successfully and contributes to the development of lifelong learners [1].

Foreign or second language learners utilize a large number of reading strategies before, during, and after reading. O'Malley and Chamot, the two prominent figures in conducting research on learning strategies, categorized learning strategies into three major categories: cognitive, metacognitive, and socioaffective [2]. The utilization of language learning strategies was later on extended to teaching and learning process of language skills. Of listening, speaking, reading, and writing skills, since 1970's EFL (English as a Foreign Language) or ESL (English as a Second Language) researchers have begun to shed light on the importance of employing different strategies during reading.

In 1991, one of the language theorists noted that both reading theory and practice have undergone so many changes in the second half of the twentieth century [3]. In this vein, researchers recently have introduced new ways for teaching reading comprehension skills to EFL/ESL learners. Among all the various types of learning strategies, the second/foreign language reading researches have long been interested in reading comprehension strategies and their relationships to successful and unsuccessful L2 reading ([4]; [5]; [6]; [7]). Two language theorists have argued that language teachers should go beyond the transmission of knowledge and should empower students by assisting them to acquire the knowledge, skills, and strategies needed to become autonomous learners and are able to take responsibility for their own learning [8].

The reading process implies the use of reading strategies. Hardebeck defines reading comprehension strategies as mental operations, tools or plans used by readers for facilitating and extending their comprehension [9]. Furthermore, reading strategies demonstrate how readers regard a task, what contextual cues they attend to, how they understand the reading passages, and what they do when they do not understand. Reading strategies ranged from 
fix-up strategies such as rereading difficult sections and guessing the meaning of an unknown word from context, to more broad strategies such as summarizing and relating what is being read to the reader's background knowledge. Different studies indicated that more and less proficient readers use strategies in different ways [10].

By taking the importance of comprehension process into account, researchers must fulfill the problem of identifying the best strategy for the purpose of contributing to its development. In line with this fact, this study examined the most frequently used reading strategy named summarizing. According to [11]" summarization is probably the most significant and encompassing of all reading strategies available to the learner for effective studying and comprehension" (p.330) [11]. The process of summarization focuses attention on the major points of the texts and provides the reader with a conceptual framework that accelerates both memory and comprehension. Summarization is based on Strategy Intervention Model (SIM) which considers students' difficulties by instructing them how to utilize strategies [12]. Knowing how to learn through instruction in summarizing strategy is the main focus of the SIM strategy.

A model of discourse comprehension was proposed in 1978[13]. This model provides a theoretical explanation of how summarizing strategy improved deep comprehension and learning. Summarizing process contributed to the goal of creating a critical foundation of factual and conceptual knowledge since it acted to strengthen the memory representation of the content beyond that achievement through reading [13].

\subsection{Significance of the Study}

The present study is significance in that it can provide notable insights to the effect of summarizing strategy on learners' reading comprehension performance.

\subsection{Purpose of the Study}

The core objective of the present study is to investigate the effect of summarizing strategy on students' reading comprehension.

\subsection{Research Question}

Accordingly, based on the mentioned facts the present study addressed the following question:

Q: Does summarizing strategy have a significant effect on reading comprehension of Iranian intermediate EFL learners?

\section{Literature Review}

Generally, reading is considered the most important skill for second /foreign language success in educational contexts ([14]; [15]; [16]; [17]).Various studies indicated that the ability to read and make sense of a text is regarded essential for students' comprehension progress. More specifically in EFL contexts such as Iran, among all the four language skills, reading viewed as the most significant and durable ones. A plethora of studies have been carried out to examine the effect of summarizing strategy on reading comprehension; however, a brief review of its effect on reading comprehension is mentioned to support the claim for the implementation of the present study. A few researches in 2006 investigated the effects of a direct instruction main idea summarization program and a self-monitoring technique on the reading comprehension of 4 sixth-grade students with learning disabilities [18]. Results indicated the main idea instructional program produced increases in identifying and generating main ideas, with even higher levels of performance following self-monitoring instruction [18].

In the English reading field, summarizing technique is useful for students in terms of reading comprehension, recalling, and organization. Generally, a vast majority of reasons may be the source of students' difficulties in reading comprehension. Factors such as lack of appropriate reading strategies, lack of background knowledge related to the topic of the passage or lack of attitudes toward reading are examples of the sources of those difficulties. Moreover, there are few teachers who are familiar with the recent strategies to provide some effective opportunities for their students. On the basis of what actually occurs in most EFL classrooms, the strategy which is frequently applied by most EFL teachers and students is the summarizing strategy. Regarding the vast improvements in the domain of reading comprehension strategies, it seems there is still a need to call for the traditional strategies along with the new strategies to provide some improvement in this domain.

Studies that have been conducted on the importance of reading strategy instruction are classified into two main categories. The first category encompasses the reader's strategy use. The findings of this category of studies have indicated that strategy use is different among less and more proficient readers ([19]; [20]). A Taiwanese researcher in 2010 explored a group of Taiwanese EFL learners' use of reading strategy [21]. This study considered three effective reading strategies of cognitive, metacognitive, and compensation strategies; their perceived impact on the learners' self-efficacy, and the relationship between reading strategy use and perceived self-efficacy on their English reading comprehension. The findings of this study demonstrated that students used metacognitive strategy most frequently, followed by compensation strategy, and finally cognitive strategy. Furthermore, a significant relationship was recognized between learners' reading strategy use and perceptions of self-efficacy [21]. Indeed, another study has been conducted on the effectiveness of language learning strategy use [22]. The study revealed that intermediate level students reported more use of learning strategies than beginning and advanced students and that more strategic language learner improved faster along the proficiency continuum than the less strategic ones [22]. The results of a research revealed that proficient readers utilize more complex approaches to reading than less proficient readers [23]. The study showed that the skilled readers utilized 
strategies of inference, summarization and synthesis during and after reading, while the less skilled readers used bridging inferences, paraphrasing and repetition. It can be concluded that high proficient readers employed more strategies while comprehending a text [23] (Yau, 2005).

The second category of the studies investigated the effect of reading strategy instruction on the readers' reading performance. A researcher examined the effect of scanning and skimming strategies on Iranian EFL learners' reading rate and reading comprehension [24]. The results showed that scanning strategy significantly improved the students' both reading rate and reading comprehension, while skimming had only a significant effect on students' reading comprehension. In still another experimental study [25] attempted to determine the effect of consciousness-raising of metacognitive strategies on Iranian EFL learners' reading comprehension. The researcher found that the experimental group showed a significant improvement in reading comprehension than the control group. A study has been carried-to determine the effect of reading strategy instruction on raising learners' reading comprehension ability, extending the range of strategies they employed and enhancing their awareness [26]. The findings of the study demonstrated that while strategy training appeared to raise students' awareness of reading strategies and could encourage strategy use by some students, the reading strategy instruction was not able to enhance the students' reading performance [26].

A brief look at the review of related literature shows that the area of reading comprehension strategy instruction still requires further research, especially in an EFL context such as Iran, the reason is that a few studies have been conducted to investigate the actual effect of teaching comprehension strategies on learners' reading comprehension performance.

\section{Method}

\subsection{Subjects}

To conduct the current study, two groups each consisting of 30 (control) and 31(experimental) students of intermediate level were selected for the purpose of this study based on the placement test. Their age ranged from 18 to 27 . All participants were foreign language learners of English. The students in intact English language classes were randomly divided into control and experimental groups, with experimental group receiving summarizing strategy for treatment and the control group was not trained on the strategy.

\subsection{Materials}

The following materials were utilized for the purpose of the present study:

English placement test. This test consisted of listening, structure and written expression, and reading comprehension sections. The test was designed to the level of the students. It was taken from Longman Preparation Course for The TOEFL Test.
Pretest and post reading comprehension test. The pretest comprised of five English passages of comparable length along with fifty multiple choice items chosen from Longman Preparation Course for The TOEFL Test. The test was utilized to measure the comprehension ability of the students in both groups before the experiment. No changes or modifications were made to the texts.

A standard and reliable test similar to the pretest was used as posttest after ten weeks of instruction at the end of the treatment. It was a reading comprehension test consisting of five passages with fifty multiple choice questions selected from Longman Preparation Course for The TOEFL Test by Deborah Philips.

Reading comprehension tests. Students were assigned with several reading comprehension passages and tasks during ten weeks of experiment (three sessions each week, 45 minutes in duration). Fifteen reading passages of appropriate length from Reading and Vocabulary Development 3 Causes and Effect by Ackert and Lee (2005) and Active Skills for Reading: Book 3 by Anderson (2013) was given to the subjects. Five reading comprehension tests were used as an immediate posttest to ensure of students' reading comprehension achievements after each two-week instruction of summarizing strategy. Each immediate posttest involved two passages with 10 multiple choice items.

\subsection{Procedures}

This is an experimental design study conducted within two and a half months. In order to conduct this study some books were utilized. The Top Notch series was the main book but along with this book the reading passages that were used to teach and test in this study were selected from two famous reading comprehension books entitled Reading and Vocabulary Development 3 Causes and Effect by Ackert and Lee (2005) and Active Skills for Reading: Book 3 by Anderson (2013). The reasons for choosing the reading passages from these two books were that since only intermediate level students were required in this study and since these books designed for intermediate learners, books of these series were selected for the purpose of this study. These books help students become more confident, independent, and active readers. All the selected passages were at the intermediate level, i.e. at the same level of the students. Fifteen similar passages from these two books were selected to practice in both control and experimental groups.

The subjects of the study were students with intermediate level selected by administering a standard TOEFL proficiency test. Prior to the study, five reading comprehension passages with 50 multiple choice questions were administered to students as a pretest. The allotted time to test administration was 55 minutes. The obtained scores from the two classes were statistically analyzed and compared to figure out whether there was any significant difference between the control and experimental groups in terms of their reading comprehension ability. Once the pre-test was administered, a treatment procedure was assigned to experimental group. The researcher (the teacher) first modeled and explicitly instructed 
the summarizing strategy with some examples to the experimental group until she was confident that each student learned how to use it properly. The teacher provided the accompanying activities so that students were motivated to use the target passages which were selected from the above mentioned books. The treatment phase consisted of three sessions of instruction in each week typically 45 minutes in duration. After explicit instruction of the strategy based on Brown and Day (1983) general rules of summarization; the reading passages were taught in each session and subjects were asked to summarize the passages at home and summit their works to the teacher. In the next session based on the subjects' summaries and their questions and problems, the researcher prepared some comments and feedback and provided them orally to all of them. The feedback given by the teacher consisted of some examples of the strong points of the summary as well as guidelines for improving the subject's summary production. The students read, shared, and discussed the reading and then completed the related exercises individually, in pairs or in small groups. And the recycle continued until the end of the experiment. With the control group, the researcher followed the ordinary approaches of teaching reading comprehension. The control group class began with previewing the topic; focusing on main points of the passage and new vocabularies. The students read the passages silently. Then the teacher taught the passage using the other ordinary strategies and approaches including skimming, scanning, and inferencing. Finally, they completed the exercises individually, in pairs or in small groups. The summarizing strategy was worked for two weeks- and then at the end of each two week instruction an immediate post-test was administered to both groups according to the strategy worked. Five immediate post-test were conducted for summarizing strategy within ten weeks of instruction. At the end of the ten weeks instruction, a reading comprehension test similar to pretest was administered to both groups as posttest.

\subsection{Data Analysis}

A standardized TOEFL proficiency test was administered to determine the general proficiency level of the students as intermediate. Prior to the treatment and in order to be ensured that there is no significant difference between the two groups in terms of their reading comprehension ability, the reading comprehension pre-test was administered to them. Therefore, all learners participated in the pre-test. The purpose was to establish a baseline from which achievements in subjects' performance on the post-test could be measured. An independent sample t-test was then run to see if the two groups performed significantly differently on the reading comprehension pre-test or not. The results obtained from this statistical analysis (Table 1) indicated no significant difference (p (0.98)> 0.05) in learners' performance on the pre-test among the control and experimental groups' subjects, that is, the two groups did not differ significantly in their performance on the reading comprehension pre-test.
Table 1. Independent t-test comparing the performance of the two groups on the reading comprehension pre-test

\begin{tabular}{lllllll}
\hline Variable & N & Mean & SD & SEM & DF & Sig \\
\hline Experimental & 31 & 26.94 & 9.14 & 1.69 & 88 & \\
Control & 30 & 25.33 & 9.01 & 1.77 & 79.6 & .98 \\
\hline
\end{tabular}

After ten weeks of instruction, all the students in both groups were given the reading comprehension post-test which was the same as the pretest. In order to see whether the treatment procedure implemented to the experimental group had any significant effect on this group and to see whether the experimental groups' was significantly different from that of the control group, an independent t-test was run between the scores of the reading comprehension post-test of both groups. The statistical results of the reading comprehension post-test are summarized in table 2 .

Table 2. Independent t-test comparing the performance of the two groups on the reading comprehension post-test

\begin{tabular}{lllllll}
\hline Variable & N & Mean & SD & SEM & DF & Sig \\
\hline Experimental & 31 & 32.94 & 14.84 & .39 & 98.2 & \\
Control & 30 & 28.73 & 10.21 & .97 & 83.6 & .03 \\
\hline
\end{tabular}

The results presented in Table 3 demonstrate significant difference in the performance of the two groups on reading comprehension test $(p=0.03, p>0.05)$, since the obtained $p$ value is smaller than $<0.05$, suggesting that reading strategy instruction was able to exert a significant effect on the reading.

In the next step, and in order to probe whether the treatment given to the experimental group had made any significant change within this group and to see if the students in this group had performed significantly differently on the post-test compared with the pre-test, the reading comprehension pre-and post-test scores of the experimental group were compared using a paired t-test. The results obtained from this statistical test are summarized in table 3.

Table 3. Paired t-test comparing the performance of the experimental group on the reading comprehension pre-and post-tests.

\begin{tabular}{llllllc}
\hline Experimental & Mean & SD & SEM & DF & t & Sig(2-tail) \\
\hline Pre-posttest & 4.677 & 1.301 & .234 & 30 & 20.018 & 0.00 \\
\hline
\end{tabular}

As the above table demonstrates, a significant difference $(p=0.000<0.05)$ was found between the performance of the students of the experimental group on the pre-and post-tests suggesting that reading comprehension strategy instruction could create a significant change on the behavior of the aforementioned group within the instruction period.

\section{Results and Discussion}

The results advocate the idea suggested by [26] noting that successful use of a reading strategy depends on different factors such as the knowledge of how to utilize that strategy which was provided through a strategy based instruction. 
Successful strategy users are both aware and flexible in the use of different reading strategies needed to do a task. This fact can stand for the present study. As it was demonstrated in the data, there was relationship between the degree of reading comprehension ability and utilizing of the summarizing strategy. In other words, students' comprehension ability enhanced when they used the mentioned strategy in comprehending the passages. This study is in line with the previous studies which have been done over the past 20 years stressing that learning strategies improve students' language skills particularly their reading skill and help them make progress in their reading tasks ([2]; [27]; [28]; [29]; [30]).To sum up the final results of the study, the current study attempted to answer the following research question. The questions will be restated and the answer, based on the findings of the study, will be provided below.

Q: Does summarizing strategy have a significant effect on reading comprehension of Iranian intermediate EFL learners?

According to the results of the analysis shown in Table 3, the answer is positive. Summarizing strategy could influence students' reading comprehension ability sufficiently and made statistically significant improvement in the students' reading ability. For years, and more recently, summarizing strategy is regarded as an important tool in reading comprehension but as revealed in the present study it is still worth to put emphasize on it.

Generally, the results of the current study demonstrated that comprehension skills and abilities can be improved by employing appropriate strategies. Strategy instruction would help learners to think thoroughly about the strategies they could apply to enhance their reading comprehension and become proficient readers.

\section{Conclusion}

As discussed in the previous sections, the principal interest of the current study was to figure out the effect of the summarizing strategy on EFL learners' reading comprehension. The findings indicated that the current study put emphasize on the importance of summarizing strategy in language classrooms. Furthermore, current stud advocated the importance of students' strategy learning. In fact as Novak argues "the central purpose of education is to empower learners to take charge of their own meaning making" and learning strategies such as summarizing strategy are powerful tools to serve such requirements [13]. The core point which is worth to mention is that provision of feedback is an important step for the students to produce better summaries. In general, practice and explanation of the required techniques are not enough and students need to be provided with appropriate feedback to make sure of their understanding.

It can be concluded that when students are exposed to summarizing strategy, they become aware of the processes that can be applied in better understanding the reading passages and they can view the passage as a whole unit in which knowledge of the parts can be reach through regarding the preceding and following sections of the passage. Having achieved an awareness of summarizing strategy, students can have a better command of a variety of practices they can use for successful summaries of the passages.

According to the findings of the current study, sufficient time is needed to develop particular reading skills and strategies such as summarizing strategy and indeed encourage content reading intending to make students ready for autonomous reading and understanding. Through the summarizing strategy instruction, teachers can identify students' weaknesses in reading comprehension and make the essential efforts to solve their comprehension problems as much as possible. Teachers can understand whether or not the students properly use summarizing strategy in reading comprehension and recognize which parts of reading comprehension are challenging for the learners or which parts are not fully considered by them. Then they can stress that successful reading comprehension would not take place unless some appropriate activities and strategies are implemented systematically.

Furthermore, instructing strategies is time consuming for a teacher who needs to take more time and effort in preparing, processing, monitoring, and evaluating the instruction. Therefore, students require enough assistance to change their status from being fully dependent on the teacher, as it was the case in the teacher-centered classrooms, to the manner of independence in the target language reading matching to the principles of the learner-centered strategies-based instruction. To achieve this aim which is presented as learner autonomy, reading strategies including summarizing strategy should be introduced first to students; in addition, they should be provided with adequate and appropriate opportunities to work on the target strategies and have a good command of their use which are useful for reading comprehension success.

Emphasizing the significance of individuals' differences and their various learning styles, this study encouraged teachers to provide opportunities for learners to become acquainted with summarizing strategy and help them match their styles with this strategy. The proposed study showed that comprehension strategies such as summarizing could be considered as an effective method for teaching and learning of reading skill.

\section{Acknowledgements}

The researcher would like to thank Dr.Khoshsima for his unfailing patience and insightful discussions.

\section{References}

[1] Rausch, A. S. (2000). Language learning strategies instruction and language use applied to foreign language reading and writing: A simplified "menu" approach. Literacy Across Cultures, 4(1), 18-24.

[2] O'Malley, M. J., \& Chamot, A. U. (1990). Learning strategies in second language aquisition. Cambridge: Cambridge University Press. 
[3] Grabe, W. (1991). Current developments in second Language reading research. TESOL Quarterly.

[4] Salataci, R., \& Akyel, A. (2002). Possible effects of strategy instruction on L1 and L2 reading. Reading in a Foreign Language, 14(1), 1-17.

[5] Mokhtari, K., \& Reichard, C. (2004). Investigating the strategic reading processes of first and second language. System, 32(3), 379-394.

[6] Lee, K. R. (2007). Strategy Awareness-Raising for Success: Reading strategy instruction in the EFL context. Unpublished doctoral dissertation, University of Maryland, CollegePark. Retrieved from http://hdl.handle.net/1903/6859

[7] Rivers, W. (1981). Teaching foreign language skills. Chicago: University of Chicago Press.

[8] Williams, M., \& Burden, R. L. (2004). Psychology for language teachers. Ernst Klett Sprachen.

[9] Harderbeck, M. M. (2006). Effectiveness and usage of reading comprehension strategies for second grade title 1 students. Unpublished Master Thesis. Minesota State University, Education Department, Minnesota.

[10] Richards, J. C., \& Renandya, W. A. (2002). Methodology in language teaching: An Anthology of current practice. Cambridge: Cambridge University Press.

[11] Corder-Ponce, W. L. (2000). Summarization interaction: Effects on foreign language comprehension and summarizationof expository texts. Reading Research and Instruction, 39(4), 329-350.

[12] Palincsar, A. S. (1987). Metacognitive strategy instruction. Exceptional Childeren, 118-124.

[13] Kintsch, W., \& Van Dijk, T. A. (1978). Toward a model of text comprehension and production. Psychological Review, 85(5), 363-394.

[14] Huang, S. C. (2006). Reading English for academic Purposes. what situational factors may motivate learners to read? System, 34, 371-383.

[15] Rahmani, M., \& Sadeghi, K. (2009). The effect of note-taking strategy training on reading comprehension and recall of Iranian EFL learners. Unpublished Master's Thesis, Urmia University, Iran, Urmia.

[16] Bahmani, M. (2009). The use of meta-cognitive strategies among Iranian EFL learners with varying levels of proficiency in reading comprehension. Unpublished master's thesis, Urmia University, Urmia, 50-79.

[17] Akkakoson, S. (2012). Raising strategic awareness of Thai EFL students of science and technology disciplines through metacognitive strategy training. $3 L$; Language, Linguistics and Literature, The Southeast Asian Journal of English Language Studies, 18(4), 35-47.

[18] Jitendraa, A. K., Colea, C. L., Hoppesa, M. K., \& Wilsona, B. (2006). Effects of a direct instruction main summarization program and self-Monitoring on reading comprehension of middle school students with learning disabilities. System, 379-396. doi:10.1080/1057356980140403
[19] Carrell, P. L. (1991). Second language reading: Reading ability or language proficiency? Applied Linguistics, 12, $159-79$.

[20] Shang, H.-F. (2010). Reading strategy use, self-efficacy, and EFL reading comprehension. Asian EFL Journal, 12(2), $18-42$.

[21] Hong-Nam, K., \& Leavellm, A. G. (2007). A comparative study of language learning strategy use in EFL contexts: Monolingual Korean and bilingual Korean-Chinese university Students. Asia Pacific Education Review, 8(1), $71-88$

[22] Bagheri, Z. (2012). Teaching reading comprehension strategies to Iranian EFL pre-university students. The Journal pf Teaching Foreign Language Skills, 4(1), 107-138.

[23] Yau, J. C. (2005). Two Mandarin readers in Taiwan: Characteristics of children with higher and lower reading proficiency levels. Journal of Research in Reading, 28(2), 108-123.

[24] Khosravi, A. A. (2000). The effect of scanning and skimming on the rate of and reading comprehension of Iranian EFL learners: Master thesis.

[25] Shokrpour, N., \& Fotovatian, S. (2009). Effects of consciousness raising of metacognitive strategies on EFL students' reading comprehension. International Journal of Applied Linguistics, 157, 75-92.

[26] Soleimani, H., \& Hajghani, S. (2013). The effect of teaching reading comprehension strategies on Iranian EFL pre-university students' reading comprehension ability. International Journal of Applied and Basic Sciences, 5(5), 594-600.

[27] Carrell, P. L. (1998). Can reading strategies be successfully taught? The Language Teacher (Online), 22(3), 55 Paragraphs.

[28] Taraban, e. a. (2004). Analytic and pragmatic factors in college students' metacognitive reading strategies. Reading Psychology, 67-81.

[29] Phakiti, A. (2006). Modeling cognitive and metacognitive strategies and their relationship to EFL reading test performance. Melborn Papers in Language Testing, 1, 53-95.

[30] Motallebzadeh, K., \& Mamdoodi, N. (2011). Language learning strategies: A key factor to improvement of TOEFL candidates' reading comprehension ability. International Journal of Linguistics, 3(1), 1-10.

[31] Aghaei, R., \& Zhang, L. J. (2012). Effects of explicit instruction in cognitive and metacognitive reading strategies on Iranian EFL students' reading performance and strategy transfer. Instructional Science, 40(6), 1063-1081.

[32] Novak, J. D. (2010). Learning, creating, and using knowledge: Concept Maps as facilitative tools in schools and corporations. Journal of e-Learning and Knowledge Society, 6(3), 21-30. 